\title{
Phlebolymphoedema: A Venous Etiology for Elephantiasis Nostras Verrucosa
}

Hourmazd Haghbayan, MD Eric A. Coomes, MD

\begin{abstract}
About the Authors:
Hourmazd Haghbayan and Eric Coomes are with the Department of Medicine, University of Toronto, Toronto, Ontario, Canada Hourmazd Haghbayan is also with the Department of Social and Preventive Medicine, Université Laval, Québec, Québec, Canada Corresponding Author Hourmazd Haghbayan: hourmazd.haghbayan@mail.utoronto.ca

Submitted: May 15, 2018. Accepted: June 10, 2018. Published: November 9, 2018. DOI: 10.22374/cjgim.v13i4.288
\end{abstract}

\begin{abstract}
Elephantiasis nostras verrucosa is the end-stage manifestation of chronic, non-filarial, lymphatic insufficiency. While primary lymphatic disorders should be excluded, lymphoedema secondary to venous hypertension is a potentially common etiology for this condition in developed nations. We present the case of a 62 -year-old woman with a four-year history of elephantiasis nostras verrucosa progressing to impairment of ambulation. Investigations for underlying pathology demonstrated the presence of bilateral chronicized deep vein thrombi, with a primary diagnosis of phelobolymphoedema being therefore retained. Following initiation of anticoagulation, wound care, and compressive bandaging, this patient was discharged to inpatient rehabilitation.

RESUME

L'Elephantiasis nostras verrucosa est la manifestation finale d'une insuffisance lymphatique chronique, non filarienne. Alors que les troubles lymphatiques primaires doivent être exclus, le lymphœdème consécutif à une hypertension veineuse est une cause potentiellement courante de cette affection dans les pays développés. Nous présentons le cas d'une femme de 62 ans présentant depuis quatre ans des antécédents d'Elephantiasis nostras verrucosa, qui évoluent progressivement en trouble de la déambulation. Les recherches sur la pathologie sous-jacente ont mis en évidence la présence bilatérale de thrombose veineuse profonde chronique, un diagnostic principal de phélobolymphoedème étant donc retenu. Après l'initiation de l'anticoagulation, du soin des plaies et du pansement compressif, ce patient a été renvoyé en réadaptation pour patients hospitalisés.
\end{abstract}

A 62-year-old woman presented with progressive, non-pitting, bilateral leg swelling. Examination revealed extensive lymphoedema with acanthosis, scaling hyperkeratosis, and ulcerations (see Images). These findings were consistent with a clinical diagnosis of elephantiasis nostras verrucosa, the end-stage swelling of the lower extremities arising from chronic, non-filarial, lymphatic insufficiency. ${ }^{1}$ Imaging revealed bilateral iliofemoral thrombi. Management included dalteparin, wound care, and compressive bandaging.
Elephantiasis nostras verrucosa is characterized by "woody fibrosis" arising from papillomatous lesions and verrucous growths, resulting in "cobblestoning." ${ }^{1}$ Conditions prohibiting lymphatic drainage, including neoplasms and heart failure may provoke this lymphostatic disorder. ${ }^{1}$ When due to phlebolymphoedema specifically, lymphatic damage results from prolonged venous hypertension, in this case from venous thrombi. ${ }^{2}$ Differential diagnoses include venous stasis, lipodermatosclerosis, myxoedema, and filarial or fungal infections (chromoblastomycosis). ${ }^{1}$ Treatment 

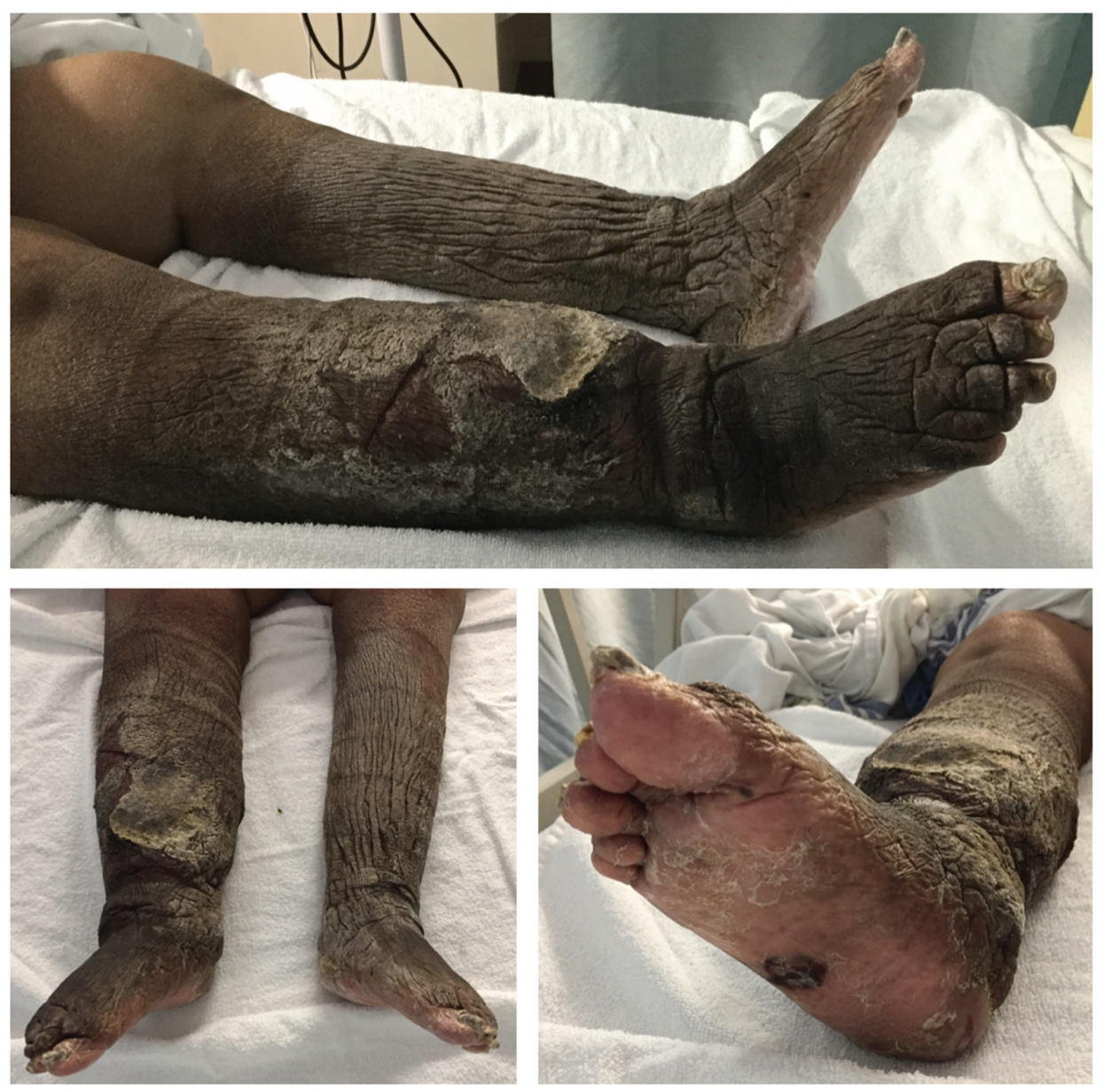

of underlying etiology is critical, including anticoagulation for venous thrombosis. Lymphoedema may be managed with compression bandages, while topical keratolytics may be used for verrucous plaques. ${ }^{1}$

\section{Consent}

The patient provided informed consent for the publication of this report following lecture of the full manuscript.

\section{Conflicts of Interest}

The authors have no actual or potential conflicts of interest to declare.

\section{Sources of Funding}

No funding was obtained specifically for this article.

\section{Contributions}

H.H. cared for the patient. H.H. and E.A.C. performed the literature search, wrote the manuscript, and revised it critically for important intellectual content.

\section{References}

1. Sisto K, Khachemoune A. Elephantiasis nostras verrucosa: a review. American J Clin Dermatol 2008;9(3):141-6. https://www.ncbi.nlm.nih.gov/ pubmed/18429642

2. Farrow W. Phlebolymphedema-A common underdiagnosed and undertreated problem in the wound care clinic. J Am Coll Cert Wound Special 2010;2(1):14-23. https://www.ncbi.nlm.nih.gov/pubmed/24527138 